\title{
Effect of Benson's Relaxation Therapy on Stress and Physiological Parameters among Women with Preeclampsia
}

\author{
Fawzia Mohamed Abd Elgwad Hassan, Specialist \\ Obstetric and Gynecologic Nursing, Faculty of Nursing, Alexandria University \\ Magda Youssef Helmy Mourad, Professor \\ Obstetric and Gynecologic Nursing, Faculty of Nursing, Alexandria University \\ Noha Mohamed Mahmoud, Assistant Professor \\ Obstetric and Gynecologic Nursing, Faculty of Nursing, Alexandria University
}

\begin{abstract}
Preeclampsia (PE) belongs to the spectrum of hypertensive disorders of pregnancy and if untreated leads to dangerous consequences for both the mother and the baby. Globally preeclampsia is responsible for 76,000 maternal and 500,000 fetal deaths each year. In developing countries around 40,000 women die each year due to PE or eclampsia. PE alone is estimated to account for about $40 \%$ to $60 \%$ of all maternal deaths (Von-Dadelszen \& Magee, 2016; WHO, 2015) In Egypt, the prevalence of preeclampsia was 6\% to 8\% of all pregnancies (WHO, 2015). Objective: Evaluate the effect of Benson's relaxation therapy on stress and physiological parameters among women with preeclampsia. Setting: The study was conducted in preeclampsia unit at El-Shatby Maternity Hospital. Subjects: A convenience sample of 80 pregnant women attending the previously mentioned setting. Tools: Three tools were used for data collection. The first tool was Women' Basic Data Structured Interview Schedule to identify data related to women' personal and socio-demographic characteristics and reproductive history. The second tool was Physiological Parameters Sheet to assess vital signs. The third tool was Cohen's Perceived Stress Scale Short Version (PSS-10) to measure subjects' level of stress. Results: The study results revealed a highly statistically significant difference between the studied groups in relation to decrease their stress level $\left(P=0.000^{*}\right)$ and maintaining physiological parameters (blood pressure value, pulse rate \& respiratory rate) within normal ranges $(P=0.000 *)$. Conclusion: Benson relaxation can be used as an effective intervention to decrease stress level and improve the physiological parameters among pre-eclamptic women. Recommendations: Benson relaxation technique is an effective intervention for pre-eclamptic women and thus should be included in the nursing care plan of this group of pregnant women.
\end{abstract}

Keywords: Benson relaxation therapy; Stress; Physiological parameters; Pre-eclamptic women.

\section{Introduction}

Pre-eclampsia (PE) is a multi-system pregnancy disease characterized by high blood pressure (BP) and involvement of one or more other organ systems, as well as effects on the health of the fetus. (Leveno et al., 2018). Globally preeclampsia is responsible for 76,000 maternal and 500,000 fetal deaths each year. In Egypt, the prevalence of preeclampsia was $6 \%$ to $8 \%$ of all pregnancies (WHO, 2015). In addition, the risks of mother-fetal complications increase in the short and long term. For the mother, this includes a two to four fold increased risk of long term high BP, a doubling of the risk of cardiovascular death and serious adverse cardiovascular events, and a one and half fold increased risk of stroke. For the embryo, this includes risks of intra-uterine growth retardation (IUGR), iatrogenic preterm birth, oligohydramnios, placental detachment, fetal distress, and intra uterine fetal death (IUFD) (Fox, Kitt, Leeson, Aye, \& Lewandowski, 2019)

The 2019 National Institute of Health and Care Excellence (NICE) guidelines assort high risk of PE as a history of high blood pressure during a previous pregnancy or as the state of health of the mother as 
chronic kidney disease, autoimmune disease, diabetes mellitus, or chronic hypertension. Moderate risk of PE if they are nulliparous, are 40 years old, have a body mass index $(\mathrm{BMI}) \geq 35 \mathrm{~kg} / \mathrm{m}^{2}$, have a family history of $\mathrm{PE}$, have twins or more pregnancies or have more than 10 years between pregnancies lie. (Bartsch, Medcalf, Park, \& Ray, 2016), there are other clinical factors that can significantly increase the risk of PE, for instance, increased mean arterial blood pressure before the 15th week of pregnancy (North et al., 2011), polycystic ovarian syndrome(Bahri Khomami et al., 2019), sleep-related breathing disorders (Pamidi et al., 2014), periodontal disease, urinary tract infections, Helicobacter pylori and other infections (Bellos, Daskalakis, \& Pergialiotis, 2018; Nourollahpour Shiadeh et al., 2019).

Maternal stress is the main risk factor for adverse pregnancy and childbirth outcomes. A meta-analysis done by Zhang et al reported that mental stress during life or pregnancy is a risk factor for gestational hypertension and PE among pregnant women. Stress stimulates various physiological systems particularly autonomic nervous system and endocrine system which associated with increase blood pressure, an increased risk of preterm birth and low birth weight.(Zhang et al., 2013).

There are controversies that surround the use of antihypertensive drugs during pregnancy on unclear tests. Therefore, there is an urgent need for new and different methods to treat hypertension during pregnancy; in particular, nonpharmacological options. Evidence that a healthy diet, weight reduction, adequate exercise and stress management could reduce the risk of preeclampsia. Studies have shown that relaxation and deep breath techniques make a lot to prepare pregnant women to face challenges and discomfort associated with childbirth. Also they have a positive effect on the fetus. Several studies are performed on the impact of relaxation techniques in hypertension. The results revealed that all relaxation therapies were effective in reducing blood pressure. Dr. Herbert Benson described a physiological response that is the opposite of the fight or the response of the flight. It translates into a decrease in metabolism, reduction of heart rate, decrease in blood pressure and reduction of the breathing rate, as well as the slower brain waves. Relaxation therapy is a simple practice that the pregnant woman can learn to take 10 to 20 minutes a day and can help relieve blood pressure and stress. (Benson \& Proctor, 2011).

Benson's relaxation technique is a simple method which helps to reduce blood pressure. Apart from the pharmacological measure, were it complicated to fetus. Nurse can implement certain non-pharmacological methods into practice for reducing $\mathrm{BP}$ in HPD mothers. Based on the studies related to the effectiveness of breathing exercises, and relaxation therapy the investigator feel it as a strong need to study the effect of Benson's relaxation therapy on antenatal mother with HPD in relation to the reduction in the level of BP.

\section{Aim of the Study}

The aim of the study is to evaluate the effect of Benson's relaxation therapy on stress and physiological parameters among women with preeclampsia.

\section{Research Hypotheses}

1. Pre-eclamptic women who receive Benson's relaxation therapy exhibit normal physiological parameters than those who don't receive it.

2. Pre-eclamptic women who receive Benson's relaxation therapy exhibit less stress level than those who don't receive it.

\section{Materials and Method}

\section{Materials}

Design: Non-randomized controlled clinical trial research design was utilized in this study. 
Setting: This study was conducted in preeclampsia unit at El-Shatby Maternity Hospital.

Subjects: The sample size was estimate using Epi info 7 statistical program using the following parameters; total population (women attending the previously mentioned settings) 71 per 3 months, Expected frequency $50 \%$, confidence level $95 \%$ and with $10 \%$ margin of error. The minimum sample size estimated to be 60 women. The final sample size was 80 women for possible non-response.

A convenience sample of 80 pregnant women attending the previously mentioned setting.

\section{Inclusion criteria:}

- Pregnant women diagnosed with mild or moderate preeclampsia.

- Staying at the hospital for 3 consecutive days.

- Free from other medical conditions.

Tools: Three tools were used:

Tool I: Basic Data Structured Interview Schedule

First part: Socio-demographic characteristics: It included age, level of education, occupation, her marital status, residence, and family income.

Second part: Reproductive history: It included gravidity, parity, number of abortions, stillbirths, previous pregnancy, labor and postpartum complications, and number, age and sex of living children.

\section{Tool II: Physiological Parameters Sheet}

Assessment of vital signs.

Tool III: Cohen's Perceived Stress Scale Short Version (PSS-10)

It was developed by (Cohen, 2012) revised version. It was adapted and used to measure subjects' level of stress. It comprised of 10 items that ask about thoughts and feelings during the last month. (Cohen, 2012) Each item was responded on a 3 point Likert scale as the following coding: Often (3 points), Sometimes (2 points) and Never (1 point). The total score for each subject ranged between $10-30$. Subjects' perceived stress level was categorized as follows: (Low stress $<17$, Average stress 17- $<24 \&$ High stress $\geq 24$ ).

\section{Method}

- Agreement of Research Ethical Committee (REC) of Faculty of Nursing Alexandria University was obtained.

- The researcher took adequate training about application of Benson relaxation technique by a specialist in mental relaxation therapy.

- Official letter from the Faculty of Nursing was submitted to the responsible authorities of the study setting to obtain their permission for data collection after explanation of the research purpose.

- Tools (I\&II) were developed by the researcher based on extensive review of recent \& relevant literature.

- Tool III was adapted and translated into Arabic language.

- The tools were submitted to five experts in the related field to assess its content validity then the necessary modifications were done.

- Tool III was tested for content reliability using Cronbach's alpha test. Reliability coefficient was reliable (0.829).

- A pilot study was carried out on 8 preeclamptic women to test the clarity, feasibility and applicability of the tools and necessary modifications were done accordingly. Pilot study participants were excluded from the study sample.

- Each pre-eclamptic woman of both groups was interviewed individually to collect the basic data (tools I\&II), For control group, they received the routine hospital care for pre-eclamptic 
woman as (history taking, physical examination, special investigations, instructions and reassurance). In addition to researcher physical presence.

- The researcher started with the control group until the required number was reached and then followed by the experimental group to avoid contamination of the sample.

- For the study group, Benson relaxation therapy was implemented through the following steps:

- Content preparation: it included presentation (demonstration) regarding Benson relaxation technique (definition, purpose, types of relaxation therapy and how it used).

- Environment preparation: woman sat calmly in a comfortable position in a quiet place.

- The researcher applied Benson relaxation technique for preeclamptic women twice per day with interval three hours apart. The procedure was repeated for three consecutive days.

- Researcher interviewed each woman in study group individually to explain how to do Benson relaxation technique by performing it while woman was watching. Then the woman was asked to redemonstrate it. As following steps:

○ Step 1: the woman was asked to pick a focus word (such as "one").

○ Step 2: the woman was asked to close her eyes.

○ Step 3: the woman was asked to progressively relax all muscles, beginning with toes and feet and moving up through entire body. o Step 4: the woman was asked to breathe slowly and naturally. As she exhales, repeat silently the focused words or phrases or focusing on breathing rhythm.

- Physiological parameters and stress were evaluated for all preeclamptic women in both groups immediately and after three days later

- After collecting the necessary data, statistical analysis of results was done.

- Collection of data consumed 10 months starting from February 2020 till the end of December 2020. The researcher used to go daily to preeclamptic unit.

\section{Ethical considerations:}

For each recruited subject the following issues were considered: Securing the subject's written informed consent after explanation of research purpose. Keeping the subject's privacy, assuring confidentiality of the subject's data, and right to withdraw at any time.

\section{Statistical Analysis}

Statistical analysis was done by the researcher after collection of data by using Statistical Package for Social Sciences (SPSS version 20) program. The collected data was categorized, coded, computerized, tabulated and analyzed using frequency distribution tables, percentage, means and standard deviations. Also, the difference sample test, student t-test, paired t test, ANOVA test, chi-square test and fissure exact test. Significance of the obtained results was judged at the $5 \%$ level.

\section{Results}

Table (1) shows number and percent distribution of the studied groups according to their socio- demographic characteristics: The same present $(62.5 \%)$ of the study and control groups were $30<40$ age group. $40 \%$ of the study group had a university level of education compared to $17.5 \%$ of the control 
group. In addition, about one third (30\%, $35 \%$ ) of the study group and control group respectively had secondary education. As much as $(72.5 \%, 87.5 \%)$ of the study and control groups respectively were housewives. $55 \%$ and $65 \%$ of the study and control groups respectively were rural dwellers. About three quarter $(75 \%)$ of the study group perceived their families' income as adequate. No statistically significant difference was found among the two groups in relation to their socio-demographic characteristics.

Table (2) portrays number and percent distribution of the studied groups according to their reproductive history. One third $(30 \%)$ and about two fifth $(42.5 \%)$ of the study and control groups respectively were primigravida. Nearly two thirds $(67.9 \%$ \& $65.2 \%$ ) of the study and control groups respectively were multipara. $87.5 \%$ \& $92.5 \%$ of study group and control group respectively had no history of abortion. about one fifth $(21.4 \%)$ and nearly three fifth $(56.5 \%)$ and of the study and control groups respectively have two child, $32.1 \%$ of the study group had previous pregnancy complications compared to $43.4 \%$ of the control group, No statistically significant difference was found among the two groups in relation to their reproductive history.

Table (3) illustrates distribution of the studied groups according to their vital signs before and after the intervention: Before intervention, the mean systolic blood pressure was $158.25 \pm 12.17$ among study group compared to $150.50 \pm 18.80$ of control group. Immediately after intervention, the mean systolic blood pressure decreased to $144.13 \pm 12.14$ among study group compared to $145.12 \pm 17.078$ of control. On third day the mean systolic blood pressure decreased to 119.25 \pm 3.311 among study group but among control group remain the same $(145.12 \pm 17.078)$ as immediately after intervention with a highly statistically significant difference between both groups $(\mathrm{P}=0.000 *)$.
In relation to the mean diastolic blood pressure before intervention was $95.20 \pm 11.17$ among study group compared to $90.75 \pm 12.19$ of control group. Immediately after intervention, the mean systolic blood pressure decreased to $87.75 \pm 9.470$ among study group compared to $87.38 \pm 9.805$ of control. On third day the mean diastolic blood pressure decreased to $77.00 \pm 4.641$ among study group but in control group remain the same (87.38 \pm 9.805$)$ as second day. With a highly statistically significant difference between both groups $(\mathrm{P}=0.000 *)$.

Before intervention the mean pulse rate was $92.28 \pm 7.229,97.78 \pm 16.26$ to the study and control group respectively, immediately after intervention it decreased to (87.40 \pm 6.088$)$ among study group and had another improvement by third day $(81.23 \pm 3.846)$. But in control group the mean pulse rate still high immediately after intervention $(93.05 \pm 10.99)$ and had no change on third day $(93.05 \pm 10.99)$. With a highly statistically significant difference between both groups $\left(\mathrm{P}=0.000^{*}\right)$.

Pregnant women who received Benson relaxation therapy experienced decline in their respiration rate immediately and on the third day of intervention compered to control group had no change, with a highly statistically significant difference between both groups $(\mathrm{P}=0.000 *)$.

Table (4) reveals distribution of the studied groups according to their stress level: Before and after the intervention. Before the intervention $97.5 \%$ of the study group had average stress level compared to $95 \%$ of the control group. Immediately after intervention Benson relaxation therapy achieved improvement among the study group where average stress level decreased to $62.5 \%$ compared to $92.5 \%$ of the control group. Another decrease to $25 \%$ on third day from intervention. Compared to no change occur among control group (92.5\%), with a highly statistically significant difference between both groups $\left(\mathrm{P}=0.000^{*}\right)$. 


\section{Discussion}

Preclampsia can have dangerous effects on both maternal and fetal health and is associated with psychological problems as stress. Benson Relaxation technique can decrease the sympathetic nervous system, allowing the arteries to widen, is increasing the availability of oxygen and blood flow to the body tissues. Moreover, it can help in decreasing blood pressure, improving stress level (Arulkumaran, Ledger, Doumouchtsis, \& Denny, 2019).

On evaluating the impact of Benson relaxation on vital signs among women have preeclampsia, the outcomes of the present study verified that high statistically significant variations among the study group before and after intervention in relation to their vital signs. They have been additionally determined among the study and the control groups after intervention. Where, the systolic blood strain value, diastolic blood strain value, the heart rate and the breathing rate have become decrease after the intervention among the study group unlike the control group (table 3 ).

This is agree with the literature that Benson relaxation is one of nonpharmacological measures that counteract the harmful effects produced by preeclampsia through inhibit sympathetic and stimulate the parasympathetic nerves system by blocking the feedback pathway from the mind, consequently prevent the biological response. So, it decreases blood pressure, heart rate and metabolic rate through producing the relaxation response (RR) (Lindquist, Tracy, \& Snyder, 2018). Moreover, Blood pressure controls during the relaxation technique due to decreased inflammation and blood vessel constriction and blood vessels widen. This mediated by nitric oxide, a molecule made in the body that helps relax and widen blood vessels, keeping blood pressure under control (Darkwa et al., 2018; Possomato-Vieira \& Khalil, 2016).
The present finding is compatible with A systematic review and meta-analysis done by Smith,. et al, (2020), titled "The safety and effectiveness of mind body interventions for women with preeclampsia" in Australia, The study revealed that relaxation found a reduction in systolic blood pressure (MD $11.3,95 \% \mathrm{CI}-13.23$ to -9.39$)$ and diastolic blood pressure (MD -6.59, 95\%CI -9.43 to 3.75) (C. A. Smith, A. Tuson, C. Thornton, \& H. G. Dahlen, 2020).

The current finding corresponds with the Egyptian study by Roma et al. study (2020) titled "The effect of Benson relaxation therapy on anxiety and the quality of sleep among preeclamptic women". The study revealed that there was statistically significant difference between the study and control groups concerning physiological parameters where highly statistically significant difference found regarding blood pressure, temperature, pulse and respiration $\mathrm{p}=(0.001 *) \quad$ (Roma, Alam, Hables, \& Nakeb, 2020).

The current finding relatively matches with the study of Mahmoudirad et al. (2017) on" The Effects of Benson's Relaxation Response on Fatigue During Pregnancy" in Iran, which concluded that relaxation therapy relieves muscular tension, decreases blood pressure and heart rate, and regulates breathing. Through Benson's relaxation response, individuals can relax all their muscles one by one and therefore, alleviate their anxiety and stress. Relaxation also stops stress response, which has been found to significantly contribute to pregnancyrelated problems, such as fatigue (Mahmoudirad, Hosseini, Nasirizade, \& Biabani, 2017).

The current finding is matching with the study of Preethi Jazna, et al, (2016) in Madurai. The study assesses the effectiveness of Benson relaxation therapy on blood pressure and stress among women with pregnancy induced hypertension. They reported that after Benson relaxation therapy among the study group almost all (96.67\%) had systolic BP $<140 \mathrm{~mm} \mathrm{Hg}$ and $83.33 \%$ 
had diastolic BP $<90 \mathrm{~mm} \mathrm{Hg}$. There was a significant reduction in mean posttest systolic $\mathrm{BP}(\mathrm{MD}=14 ., \mathrm{t}=21.03 ., \mathrm{p}<0.05)$ and diastolic blood pressure( $\mathrm{MD}=9$., $\mathrm{t}=12.41$., $\mathrm{p}<0.05$ ) (Preethi Jazna, Jebakumari, \& Santha, 2016).

The same result is also in congruent with the findings of a study done by Komathi (2014) regarding the effectiveness of Benson's relaxation therapy on level of blood pressure among Indian preclamptic women. The findings revealed that there was statistically significant difference in the post assessment level of systolic and diastolic BP among study group and control group. Benson's relaxation therapy significantly reduces the blood pressure (Komathi, 2014).

The present finding is in line with the study of Mini, (2012), titled "effectiveness of Benson's relaxation therapy on blood pressure among mothers with PIH". The findings revealed that the mean value of the pretest systolic blood pressure was 154.80 with S.D 7.49 and in the post test the mean value was 129.37 with S.D 5.42 with the mean difference of 25.43 this indicated that there was a high significant difference in blood pressure level at $\mathrm{p}<0.001$ (Mini, 2012).

Generally speaking, stress in pregnancy corroborates the physiopathology of preeclampsia as it reduces uteroplacental blood flow through the excretion of corticosteroids and catecholamines which are known to exert strong vasoconstrictor effects on the tone of peripheral blood vessels. Besides, the placenta is abundant of receptors for these hormones. Activation of the sympathetic nervous system by stress may lead to reduced blood flow to the uterus and fetus, and may contribute to preeclampsia.

Concerning the average score of stress level pre and post intervention, the present study results revealed that the level of stress among the study group was significantly decreased after practicing Benson's relaxation therapy (table 4 ). This may be interpreted by practicing Benson's relaxation therapy leading to improve the relaxation response which is personal ability to make the body release chemicals and brain signals that make the muscles and organs slow down and increases blood flow to the brain (Information Resources Management, 2019). Also, all relaxation response techniques are characterized by reduced stress hormones and reduced central nervous system activity in the form of measurable brain wave changes. Studies revealed a statistically significant positive correlation between the preeclampsia and level of psychosocial stress. PE is associated with an increased stress level. These results were again supported by the relevant literature which emphasized that maternal stress in pregnancy is associated with preeclampsia.

The present finding is relatively compatible with the results of Iranian study conducted by Zenouzi, et al. (2021) titled "The effect of Benson relaxation technique on stress, anxiety, and depression in pregnant women". They had reported that Benson Relaxation therapy can be effective in establishing psychological tranquility for maternal and fetal health. Help in reduction of the stress, anxiety, and depression in pregnant women (Zenouzi, Moghadam, Babayanzad, Asghari, \& Rezaei, 2021).

The current finding is relatively similar to Australian study of Smith, et al. (2020), The study revealed that relaxation therapy had been beneficial in reducing stress during pregnancy among preeclamptic women (C. A. Smith, A. Tuson, Charlene Thornton, \& Hannah G. Dahlen, 2020).

Moreover, the present finding is supported by the Mohammad, (2019) in his study about "Effect of the combination of Benson's relaxation technique (BRT) and brief psychoeducational intervention (BPI) on multidimensional pain and stress among pregnant women. The results of this study suggested that the combination of BRT and BPI can lead to a reduction in stress and 
multidimensional pain in the pregnant women (Mohammad \& Shima, 2019).

Likewise, the current finding is similar to the study of El-Sayed, (2017), titled "Benson's relaxation therapy: its effect on stress and coping among mothers with high risk pregnancy" in Egypt. The results of this study reported that the average score of stress scale was significantly decreased postintervention (13.84 \pm 2.53 ) (El-Sayed, 2017).

The current finding fits with the study of Paramban, et al. (2016), titled "Effectiveness of Benson's relaxation therapy on reduction of stress among primigravid mothers" in Curacao, Netherland Antilles, which indicated that significant reduction was observed in stress scores before and after practicing intervention among primigravid mothers (Paramban, Arja, J, Rao, \& Kottath Veetil, 2016).

In addition, the previously mentioned study of Kiron, et al. (2012), in India, The study reported that highly significant difference was observed in stress scores before and after practicing intervention among preeclamptic women (Kiron, Salins, \& Saritha, 2012).

\section{Conclusion}

Based on the findings of the present study, it can be concluded that: Hypothesis (H1) and hypothesis (H2) are accepted as the results revealed that Benson relaxation therapy (BRT) has a beneficial effect in reducing stress level among preclamptic women. Also, it has a remarkable effect on maintaining physiological parameters (blood pressure value, pulse rate $\&$ respiratory rate) within normal ranges.

\section{Recommendations}

In line with the findings of the study, the following recommendations are made:

- Benson relaxation therapy should be integrated as antenatal and preeclamptic care into the routine nursing care plan to increase the efficiency and quality of nursing care.

- The issue of relaxation technique as BRT regarding preclampsia is recommended to be included within maternity and gynecological nursing curricula at different nursing educational institutions.

- In service training programs asworkshops and conferences- should be carried out periodically for nurses to ensure that they are aware about BRT, its advantages and how to apply it. 
Table (1): Distribution of the studied women according to their socio-demographic characteristics

\begin{tabular}{|c|c|c|c|c|c|c|}
\hline \multirow{2}{*}{\multicolumn{2}{|c|}{ Socio-demographic characteristics }} & \multicolumn{2}{|c|}{ Study Group } & \multicolumn{2}{|c|}{ Control Group } & \multirow{3}{*}{$\begin{array}{c}\text { Test of significance } \\
\begin{array}{c}X 2=0.159 \\
P\end{array}=0.984\end{array}$} \\
\hline & & \multirow{2}{*}{$\begin{array}{c}\mathbf{n}=\mathbf{4 0} \\
5 \\
10 \\
25\end{array}$} & \multirow{2}{*}{$\begin{array}{c}\% \\
12.5 \\
25.0 \\
62.5\end{array}$} & \multirow{2}{*}{$\begin{array}{c}\mathbf{n}=\mathbf{4 0} \\
4 \\
11 \\
25\end{array}$} & \multirow{2}{*}{$\begin{array}{c}\% \\
10 \\
27.5 \\
62.5\end{array}$} & \\
\hline Age & $\begin{array}{ll}- & <20 \\
- & 20-30 \\
- & 30<40\end{array}$ & & & & & \\
\hline \multicolumn{2}{|l|}{ Mean+SD } & \multicolumn{2}{|c|}{$29.45 \pm 6.965$} & \multicolumn{2}{|c|}{$29.68 \pm 6.518$} & $\begin{array}{l}\mathrm{t}=0.022 \\
\mathrm{P}=0.882\end{array}$ \\
\hline $\begin{array}{l}\text { Level of } \\
\text { education }\end{array}$ & $\begin{array}{ll}- & \text { Illiterate } \\
- & \text { Read \& Write } \\
- & \text { Secondary } \\
- & \text { University }\end{array}$ & $\begin{array}{c}4 \\
8 \\
12 \\
16\end{array}$ & $\begin{array}{l}10.0 \\
20.0 \\
30.0 \\
40.0\end{array}$ & $\begin{array}{c}4 \\
15 \\
14 \\
7\end{array}$ & $\begin{array}{l}10.0 \\
37.5 \\
35.0 \\
17.5\end{array}$ & $\mathrm{X} 2=0.5 .806 \mathrm{P}=0.121$ \\
\hline Occupation & $\begin{array}{ll}- & \text { Housewife } \\
- & \text { working }\end{array}$ & $\begin{array}{l}29 \\
11\end{array}$ & $\begin{array}{l}72.5 \\
27.5\end{array}$ & $\begin{array}{c}35 \\
5\end{array}$ & $\begin{array}{l}87.5 \\
12.5\end{array}$ & $\begin{array}{c}X 2=2.812 \\
P=0.093\end{array}$ \\
\hline $\begin{array}{l}\text { Place of } \\
\text { residence }\end{array}$ & $\begin{array}{ll}- & \text { Urban } \\
- & \text { Rural }\end{array}$ & $\begin{array}{l}18 \\
22\end{array}$ & $\begin{array}{l}45.0 \\
55.0\end{array}$ & $\begin{array}{l}14 \\
26\end{array}$ & $\begin{array}{l}35.0 \\
65.0\end{array}$ & $\begin{array}{c}X 2=0.833 \\
P=0.361\end{array}$ \\
\hline Marital status & - Married & 40 & 100 & 40 & 100 & - \\
\hline $\begin{array}{l}\text { Income of the } \\
\text { family }\end{array}$ & $\begin{array}{ll}- & \text { Enough and save } \\
- & \text { Enough } \\
- & \text { Not enough }\end{array}$ & $\begin{array}{c}7 \\
30 \\
3\end{array}$ & $\begin{array}{c}17 \\
75.5 \\
7.5\end{array}$ & $\begin{array}{c}7 \\
23 \\
10\end{array}$ & $\begin{array}{l}17.5 \\
57.5 \\
25.0\end{array}$ & $\begin{array}{c}X 2=4.694 \\
P=0.096\end{array}$ \\
\hline
\end{tabular}

Table (2): Distribution of the studied groups according to their reproductive history

\begin{tabular}{|c|c|c|c|c|c|c|}
\hline \multirow{3}{*}{\multicolumn{2}{|c|}{ Items }} & \multicolumn{4}{|c|}{ Groups } & \multirow{3}{*}{ Test of Significance } \\
\hline & & \multicolumn{2}{|c|}{$\begin{array}{c}\text { Study group } \\
(n=40)\end{array}$} & \multicolumn{2}{|c|}{$\begin{array}{c}\text { Control group } \\
(n=40)\end{array}$} & \\
\hline & & No. & $\%$ & No. & $\%$ & \\
\hline \multicolumn{7}{|c|}{ Gravidity } \\
\hline & Primigravida & 12 & 30.0 & 17 & 42.5 & \multirow{3}{*}{$\mathrm{X} 2=3.730 \quad \mathrm{P}=0.292$} \\
\hline & Multigravida & 13 & 32.5 & 10 & 25 & \\
\hline & Grand multigravida $(\geq 4)$ & 15 & 37.5 & 13 & 32.5 & \\
\hline \multicolumn{2}{|c|}{ Parity } & \multicolumn{2}{|c|}{$\mathrm{N}=\mathbf{2 8}$} & \multicolumn{2}{|c|}{$\mathrm{N}=\mathbf{2 8}$} & \\
\hline- & Primipara & 3 & 10.7 & 6 & 26.1 & \\
\hline- & Multipara & 19 & 67.9 & 20 & 65.2 & \\
\hline \multirow{2}{*}{\multicolumn{2}{|c|}{$\begin{array}{ll}- & \text { Grand multipara }(\geq 4) \\
& (\text { Mean } \pm \text { SD }) \\
\end{array}$}} & 6 & 21.4 & 2 & 8.7 & $\mathrm{X} 2=3.281 \quad \mathrm{P}=0.350$ \\
\hline & & \multicolumn{2}{|c|}{$1.45 \pm 1.28$} & \multicolumn{2}{|c|}{$1.33 \pm 1.67$} & $t=0.141 \quad P=0.708$ \\
\hline \multicolumn{2}{|c|}{ Number of abortions } & \multicolumn{2}{|c|}{$\mathrm{N}=\mathbf{4 0}$} & \multicolumn{2}{|c|}{$\mathrm{N}=40$} & \\
\hline & Yes & 5 & 12.5 & 3 & 7.5 & $\mathrm{X} 2=0.556 \quad \mathrm{P}=0.456$ \\
\hline- & No & 35 & 87.5 & 37 & 92.5 & \\
\hline \multicolumn{2}{|c|}{ Number of living children } & \multicolumn{2}{|c|}{$\mathrm{N}=\mathbf{2 8}$} & \multicolumn{2}{|c|}{$\mathbf{N}=\mathbf{2 3}$} & \\
\hline & No living children & 5 & 17.9 & 3 & 13.1 & \\
\hline- & One & 13 & 46.4 & 6 & 26.1 & $\mathrm{X} 2=7.035 \quad \mathrm{P}=0.071$ \\
\hline- & Two & 6 & 21.4 & 13 & 56.5 & \\
\hline- & Three and more & 4 & 14.3 & 1 & 4.3 & \\
\hline \multicolumn{2}{|c|}{ Previous pregnancy complications } & \multicolumn{2}{|c|}{$\mathrm{N}=28$} & \multicolumn{2}{|c|}{$\mathrm{N}=23$} & \\
\hline & Yes & 9 & 32.1 & 10 & 43.4 & $X 2=1410$ \\
\hline- & No & 19 & 67.9 & 13 & 56.6 & $X Z=1.410 \quad P=0.253$ \\
\hline \multicolumn{2}{|c|}{ Previous pregnancy complications ${ }^{\#}$} & \multicolumn{2}{|c|}{$\mathbf{N}=9$} & \multicolumn{2}{|c|}{$\mathbf{N}=\mathbf{1 0}$} & \\
\hline- & Anemia & 4 & 44.4 & 6 & 60.0 & \\
\hline- & Vaginal bleeding & 8 & 88.8 & 8 & 80.0 & \\
\hline- & Hypertension & 4 & 44.4 & 4 & 40.0 & $\mathrm{X} 2=2.222 \quad \mathrm{P}=0.695$ \\
\hline- & DVT & 1 & 11.1 & 0 & 0.0 & \\
\hline
\end{tabular}


Table (3): Distribution of the studied groups according to their vital signs before and after the intervention over time

\begin{tabular}{|c|c|c|c|c|c|c|c|}
\hline \multirow{3}{*}{\multicolumn{2}{|c|}{ Items }} & \multicolumn{2}{|c|}{ Before intervention } & \multicolumn{2}{|c|}{$\begin{array}{c}\text { Immediately } \\
\text { (After) }\end{array}$} & \multicolumn{2}{|c|}{$\begin{array}{c}\text { Third day } \\
\text { (After) }\end{array}$} \\
\hline & & $\begin{array}{l}\text { Study } \\
\text { group } \\
(n=40)\end{array}$ & $\begin{array}{c}\text { Control } \\
\text { group } \\
(\mathrm{n}=40)\end{array}$ & $\begin{array}{l}\text { Study } \\
\text { group } \\
(\mathrm{n}=40)\end{array}$ & $\begin{array}{c}\text { Control } \\
\text { group } \\
(n=40)\end{array}$ & $\begin{array}{l}\text { Study } \\
\text { group } \\
(\mathrm{n}=40)\end{array}$ & $\begin{array}{c}\text { Control } \\
\text { group } \\
(\mathrm{n}=40)\end{array}$ \\
\hline & & No. & No. & No. & No. & No. & No. \\
\hline $\begin{array}{l}\text { Systolic } \\
\text { BL.P }\end{array}$ & Mean \pm SD & $158.25 \pm 12.17$ & $150.50 \pm 18.80$ & $144.13 \pm 12.14$ & $145.12 \pm 17.078$ & $119.25 \pm 3.311$ & $145.12 \pm 17.078$ \\
\hline \multicolumn{2}{|c|}{$P$ value between group } & \multicolumn{2}{|c|}{$\mathrm{t}=0.635 \quad \mathrm{P}=0.527$} & \multicolumn{2}{|c|}{$\mathrm{t}=0.298 \quad \mathrm{P}=0.766$} & \multicolumn{2}{|c|}{$\mathrm{t}=9.405 \quad \mathrm{P}=0.000^{*}$} \\
\hline $\begin{array}{l}\text { Diastolic } \\
\text { BL.P }\end{array}$ & Mean \pm SD & $95.20 \pm 11.17$ & $90.75 \pm 12.19$ & $87.75 \pm 9.470$ & $87.38 \pm 9.805$ & $77.00 \pm 4.641$ & $87.38 \pm 9.805$ \\
\hline \multicolumn{2}{|c|}{$P$ value between group } & \multicolumn{2}{|c|}{$\mathrm{t}=2.085 \quad \mathrm{P}=0.076$} & \multicolumn{2}{|c|}{$\mathrm{t}=0.172 \quad \mathrm{P}=0.864$} & $\mathrm{t}=6.052$ & $\mathrm{P}=0.000^{*}$ \\
\hline Pulse & Mean \pm SD & $92.28 \pm 7.229$ & $97.78 \pm 16.26$ & $87.40 \pm 6.088$ & $93.05 \pm 10.99$ & $81.23 \pm 3.846$ & $93.05 \pm 10.987$ \\
\hline \multicolumn{2}{|c|}{$P$ value between group } & \multicolumn{2}{|c|}{$\mathrm{t}=1.955 \quad \mathrm{P}=0.056$} & \multicolumn{2}{|c|}{$\mathrm{t}=2.844 \mathrm{P}=0.006^{*}$} & $t=6.420$ & $\mathrm{P}=0.000^{*}$ \\
\hline Respiration & Mean \pm SD & $21.45 \pm 2.195$ & $22.83 \pm 2.899$ & $20.67 \pm 1.207$ & $22.42 \pm 2.659$ & $18.55 \pm 1.239$ & $22.42 \pm 2.659$ \\
\hline \multicolumn{2}{|c|}{$P$ value between group } & \multicolumn{2}{|c|}{$\mathrm{t}=2.400 \quad \mathrm{P}=0.019 *$} & \multicolumn{2}{|c|}{$\mathrm{t}=4.663 \quad \mathrm{P}=0.000^{*}$} & $\mathrm{t}=8.344$ & $\mathrm{P}=0.000^{*}$ \\
\hline
\end{tabular}

Table (4): Distribution of the studied groups according to their stress level before and after the intervention

\begin{tabular}{|c|c|c|c|c|c|c|c|c|c|c|c|c|}
\hline \multirow{3}{*}{ Stress } & \multicolumn{4}{|c|}{ Before intervention } & \multicolumn{4}{|c|}{$\begin{array}{c}\text { Immediately } \\
\text { (After) }\end{array}$} & \multicolumn{4}{|c|}{$\begin{array}{c}\text { Third day } \\
\text { (After) }\end{array}$} \\
\hline & \multicolumn{2}{|c|}{$\begin{array}{l}\text { Study } \\
\text { group } \\
(\mathrm{n}=40)\end{array}$} & \multicolumn{2}{|c|}{$\begin{array}{c}\text { Control } \\
\text { group } \\
(n=40)\end{array}$} & \multicolumn{2}{|c|}{$\begin{array}{l}\text { Study } \\
\text { group } \\
(n=40)\end{array}$} & \multicolumn{2}{|c|}{$\begin{array}{c}\text { Control } \\
\text { group } \\
(n=40)\end{array}$} & \multicolumn{2}{|c|}{$\begin{array}{l}\text { Study } \\
\text { group } \\
(\mathrm{n}=40)\end{array}$} & \multicolumn{2}{|c|}{$\begin{array}{l}\text { Control } \\
\text { group } \\
(\mathrm{n}=\mathbf{4 0})\end{array}$} \\
\hline & No. & $\%$ & No & $\%$ & No & $\%$ & No. & $\%$ & No & $\%$ & No & $\%$ \\
\hline Normal & 0 & 0.0 & 2 & 5.0 & 15 & 37.5 & 0 & 0.0 & 30 & 75 & 0 & 0.0 \\
\hline Average & 39 & 97.5 & 38 & 95.0 & 25 & 62.5 & 37 & 92.5 & 10 & 25 & 37 & 92.5 \\
\hline High & 1 & 2.5 & 0 & 0.0 & 0 & 0.0 & 3 & 7.5 & 0 & 0.0 & 3 & 7.5 \\
\hline $\begin{array}{l}\text { P value } \\
\text { between } \\
\text { group }\end{array}$ & \multicolumn{4}{|c|}{$\begin{array}{cc}X=5.013 & P=0.681 \\
t=1.484 & P=0.142\end{array}$} & \multicolumn{2}{|c|}{$\begin{aligned} X & =6.135 \\
t & =0.978\end{aligned}$} & \multicolumn{2}{|c|}{$\begin{array}{l}\mathrm{P}=0.013^{*} \\
\mathrm{P}=0.063\end{array}$} & \multicolumn{4}{|c|}{$\begin{array}{l}\mathrm{X}=9.127 \mathrm{P}=0.010^{*} \\
\mathrm{t}=8.744 \quad \mathrm{P}=0.000^{*}\end{array}$} \\
\hline $\begin{array}{l}X^{2}=\text { Chi } S \\
F \text { ANOVA }\end{array}$ & & & $\begin{array}{l}X^{2} c o t \\
t=p a\end{array}$ & $d$ t test & & & & & & & cross & \\
\hline
\end{tabular}




\section{References}

- Arulkumaran, S., Ledger, W., Doumouchtsis, S., \& Denny, L. (2019). Oxford Textbook of Obstetrics and Gynaecology: Oxford University Press.

- Bahri Khomami, M., Joham, A. E., Boyle, J. A., Piltonen, T., Silagy, M., Arora, C., Moran, L. J. (2019). Increased maternal pregnancy complications in polycystic ovary syndrome appear to be independent of obesity-A systematic review, metaanalysis, and meta-regression. Obes Rev, 20(5), 659-674. doi: 10.1111/obr.12829.

- Bartsch, E., Medcalf, K. E., Park, A. L., \& Ray, J. G. (2016). Clinical risk factors for pre-eclampsia determined in early pregnancy: systematic review and metaanalysis of large cohort studies. BMJ, 353, i1753. doi: $10.1136 / \mathrm{bmj} . \mathrm{i} 1753$.

- Bellos, I., Daskalakis, G., \& Pergialiotis, V. (2018). Helicobacter pylori infection increases the risk of developing preeclampsia: A meta-analysis of observational studies. Int $J$ Clin Pract, 72(2). doi: 10.1111/ijcp.13064.

- Benson, H., \& Proctor, W. (2011). Relaxation Revolution: The Science and Genetics of Mind Body Healing: Scribner.

- Cohen, S. (2012). Review of the Psychometric Evidence of the Perceived Stress Scale. Asian Nursing Research, 6, 121-127.

- Darkwa, Ebenezer Owusu, Djagbletey, Robert, Essuman, Raymond, Sottie, Daniel, Dankwah, Gifty Boatemaa, \& Aryee, George. (2018). Nitric Oxide and PreEclampsia: A Comparative Study in Ghana. Open access Macedonian Journal of Medical Sciences, 6(6), 1023-1027. doi: 10.3889/oamjms.2018.252.

- El-Sayed, Hanan. (2017). Benson's Relaxation Therapy: Its effect on Stress and Coping among Mothers with High Risk Pregnancy. International Journal of Nursing Didactics, $7 . \quad$ doi: 10.15520/ijnd.2017.vol7.iss6.226.16-25.

- Fox, R., Kitt, J., Leeson, P., Aye, C. Y. L., \& Lewandowski, A. J. (2019).
Preeclampsia: Risk Factors, Diagnosis, Management, and the Cardiovascular Impact on the Offspring. J Clin Med, 8(10). doi: $10.3390 / \mathrm{jcm} 8101625$

- Information Resources Management, Association (Ed.). (2019). Complementary and Alternative Medicine: Breakthroughs in Research and Practice. Hershey, PA, USA: IGI Global.

- Kiron, Ss, Salins, Alice, \& Saritha, M. (2012). Effect of Relaxation Therapy on Mild Pregnancy Induced Hypertension. International Journal of Pharmaceutical and Chemical Science.

- Komathi, V. (2014). A study to assess the effectiveness of Bensož $\mathrm{s}$ relaxation therapy on level of blood pressure among Pregnancy Induced Hypertensive mothers in Institute of Obstetrics and Gynaecology Hospital, Egmore.

- Leveno, K.J., Spong, C.Y., Dashe, J.S., Casey, B.M., Hoffman, B.L., Cunningham, F.G., \& Bloom, S.L. (2018). Williams Obstetrics, 25th Edition: McGraw-Hill Education.

- Lindquist, R, Tracy, M, \& Snyder, M. (2018). Complementary and alternative therapies in nursing. Retrieved from https://search.ebscohost.com/login.aspx?dir ect $=$ true $\&$ scope $=$ site $\& d b=$ nlebk $\& d b=$ nlabk $\underline{\mathrm{AN}}=1716761$.

- Mahmoudirad, G., Hosseini, M., Nasirizade, M., \& Biabani, F. (2017). The Effects of Benson's Relaxation Response on Fatigue During Pregnancy: A TwoGroup Randomized Controlled Field Trial. Mod Care J, 14(3), e66965. doi: 10.5812/modernc.66965.

- Mini, Abraham. (2012). effectiveness of Benson's relaxation therapy on blood pressure among mothers with PIH at selected hospitals. (Master), Omayal Achi College of Nursing, chennai.

- Mohammad, M, \& Shima, P. (2019). Effect of the combination of Benson\&\#39;s relaxation technique and brief psychoeducational intervention on multidimensional pain and negative 
psychological symptoms of pregnant women: A randomized controlled trial. Journal of Education and Health Promotion, 8(1), 91-91. doi: 10.4103/jehp.jehp_286_18.

- North, R. A., McCowan, L. M., Dekker, G. A., Poston, L., Chan, E. H., Stewart, A. W., Kenny, L. C. (2011). Clinical risk prediction for pre-eclampsia in nulliparous women: development of model in international prospective cohort. BMJ, 342, d1875. doi: 10.1136/bmj.d1875.

- Nourollahpour Shiadeh, M., Riahi, S. M., Adam, I., Saber, V., Behboodi Moghadam, Z., Armon, B., Rostami, A. (2019). Helicobacter pylori infection and risk of preeclampsia: a systematic review and meta-analysis. J Matern Fetal Neonatal Med, 32(2), 324-331. doi: $10.1080 / 14767058.2017 .1378331$

- Pamidi, S., Pinto, L. M., Marc, I., Benedetti, A., Schwartzman, K., \& Kimoff, R. J. (2014). Maternal sleep-disordered breathing and adverse pregnancy outcomes: a systematic review and metaanalysis. Am J Obstet Gynecol, 210(1), 52 e51-52 e14. doi: 10.1016/j.ajog.2013.07.033.

- Paramban, Simi, Arja, Sireesha Bala, J, Krishna, Rao, M., \& Kottath Veetil, Praveen. (2016). Effectiveness of Benson's Relaxation Therapy on Reduction of Stress among Primigravid Mothers. Acta Medica International, 3, 133-140. doi: 10.5530/ami.2016.2.27.

- Possomato-Vieira, J. S., \& Khalil, R. A. (2016). Mechanisms of Endothelial Dysfunction in Hypertensive Pregnancy and Preeclampsia. Adv Pharmacol, 77, 361431. doi: 10.1016/bs.apha.2016.04.008.

- Preethi Jazna, B., Jebakumari, R., \& \& Santha, N. . (2016). A Study to Assess the Effectiveness of Benson Relaxation Therapy on Blood Pressure and Stress Among Women with Pregnancy Induced Hypertension in Selected Hospitals. Asian Journal of Nursing Education and Research, 6(2), 167-170.

- Roma, N, Alam, T, Hables, R, \& Nakeb, M. (2020). The effect of Benson relaxation therapy on anxiety and the quality of sleep among preeclamptic women. International Journal for Research in Health Sciences and Nursing (ISSN: 2208-2670), 6(6), 0116.

- Smith, C. A., Tuson, A., Thornton, C., \& Dahlen, H. G. (2020). The safety and effectiveness of mind body interventions for women with pregnancy induced hypertension and or preeclampsia: A systematic review and meta-analysis. Complement Ther Med, 52, 102469. doi: 10.1016/j.ctim.2020.102469.

- Smith, C. A., Tuson, A., Thornton, Charlene, \& Dahlen, Hannah G. (2020). The safety and effectiveness of mind body interventions for women with pregnancy induced hypertension and or preeclampsia: A systematic review and meta-analysis. Complementary Therapies in Medicine, 52, 102469.

doi: https://doi.org/10.1016/j.ctim.2020.102469.

- Von-Dadelszen, P., \& Magee, L. A. (2016). Preventing deaths due to the hypertensive disorders of pregnancy. Best Pract Res Clin Obstet Gynaecol, 36, 83-102. doi: 10.1016/j.bpobgyn.2016.05.005.

- WHO. (2015). Trends in maternal mortality: 1990 to 2015. Estimates by WHO, UNICEF, UNFPA. The World Bank and the United Nations Population Division. Geneva: Retrieved from https://www.WHO.int.

- Zenouzi, A., Moghadam, Z. B., Babayanzad, S., Asghari, M., \& Rezaei, E. (2021). The Effect of Benson Relaxation Technique on Stress, Anxiety, and Depression in Pregnant Women. Holist Nurs Pract. doi: 10.1097/hnp.0000000000000463.

- Zhang, S., Ding, Z., Liu, H., Chen, Z., Wu, J., Zhang, Y., \& Yu, Y. (2013). Association between mental stress and gestational hypertension/preeclampsia: a metaanalysis. Obstet Gynecol Surv, 68(12), 825834. doi: 10.1097/ogx.0000000000000001. 